\title{
Cerebrovascular disease in end-stage kidney disease
}

\author{
Kazuhiko Tsuruya ${ }^{1,2^{*}}$ and Kiichiro Fujisaki ${ }^{2}$
}

\begin{abstract}
Chronic kidney disease (CKD) is an independent risk factor for cardiovascular disease and also increases the incidence of cerebrovascular disease. Prevention and management of cerebrovascular disease in patients with CKD, especially endstage kidney disease (ESKD), are different from those without CKD because of their specific pathophysiology. In patients with ESKD on hemodialysis, a decrease in brain blood flow due to a decline in blood pressure during hemodialysis might cause incident cerebrovascular disease. Cerebral microbleeds detected by magnetic resonance imaging, which are much more prevalent in patients with CKD compared with the general population, might also cause incident brain hemorrhage. For management for the hyperacute phase of brain infarction, thrombolytic therapy using recombinant tissue plasminogen activator has been recently indicated for those patients. However, this indication should be carefully evaluated because the risk of adverse events is higher in patients with CKD, especially ESKD. More recently, mechanical thrombectomy has also been applied clinically. However, the efficacy of this treatment remains unknown in CKD and ESKD patients. With regard to prevention, carotid endarterectomy and carotid artery stenting are performed for severe carotid artery stenosis. Similarly to the treatment described above, the indication for these procedures should be carefully evaluated because the incidence of stroke, myocardial infarction, and mortality is considered to be high in patients with CKD. Administration of warfarin to hemodialysis patients with atrial fibrillation is controversial because whether atrial fibrillation is involved in incident brain infarction and whether warfarin prevents cerebrovascular disease remain unknown in those patients. Novel oral anticoagulants are now available but are prohibited in severe CKD patients. Further investigation and accumulation of evidence are required for prevention and management of cerebrovascular disease in patients with CKD, especially ESKD.
\end{abstract}

Keywords: Atrial fibrillation, Carotid endarterectomy, Carotid artery stenting, Cerebral microbleeds, End-stage kidney disease, Hemodialysis, Mechanical thrombectomy, Novel oral anticoagulants, Thrombolytic therapy

\section{Background}

The prevalence and mortality of cerebrovascular disease are much higher in patients with chronic kidney disease (CKD), especially those with end-stage kidney disease (ESKD) compared with those without CKD. Therefore, prevention and appropriate management of cerebrovascular disease are crucial in this patient population $[1,2]$. However, there are many differences in the methods of prevention and management of cerebrovascular disease between patients with and without CKD, especially those with and without ESKD on hemodialysis.

\footnotetext{
* Correspondence: tsuruya@intmed2.med.kyushu-u.ac.jp

'Department of Integrated Therapy for Chronic Kidney Disease, Graduate School of Medical Sciences, Kyushu University, 3-1-1 Maidashi, Higashi-ku, Fukuoka 812-8582, Japan

${ }^{2}$ Department of Medicine and Clinical Science, Graduate School of Medical Sciences, Kyushu University, Fukuoka, Japan
}

This review describes the characteristics, prevention, and management of cerebrovascular disease in patients with CKD, especially in ESKD, with a focus on the differences in CKD compared with those without CKD.

\section{Review}

Characteristics of cerebrovascular disease in patients with CKD

Effect of CKD on incident cerebrovascular disease

The prevalence of CKD in patients with cerebrovascular disease is $20-35 \%$ and $20-46 \%$ in patients with brain infarction and brain hemorrhage, respectively. Recent prospective studies have demonstrated that renal dysfunction and proteinuria are independent risk factors for incident cerebrovascular disease [2]. In contrast to a decrease in brain hemorrhage, the proportion of brain 
infarction is increasing. A possible reason for this finding could be developments in hemodialysis that have led to expansion of the indications for hemodialysis among older patients with multiple risk factors. In addition, use of erythropoiesis-stimulating agents to treat anemia might, to some extent, have increased thromboembolic events. A possible reason for the relative decrease in brain hemorrhage could be a decrease in heparin dose during dialysis according to improvement in dialysis membranes. Additionally, low-molecular weight heparin instead of unfractionated heparin has been used for patients at high risk for hemorrhagic complications, although this has not frequently been performed [3].

\section{Effect of CKD on the severity of cerebrovascular disease}

CKD is considered to affect not only the incidence of cerebrovascular disease but also its severity. In the Fukuoka Stroke Registry Study, it was reported that patients with CKD had significantly higher risks of neurological deterioration, in-hospital mortality, and poor functional outcome $[4,5]$. These reports also demonstrated that among the CKD components, a higher urinary protein level was associated with an elevated risk of each outcome. Severity of cerebrovascular disease is more prominent in dialysis patients compared to those with non-dialysis dependent CKD, and brain hematoma after hemorrhagic stroke is larger and the prognosis is poorer in hemodialysis patients $[1,2,6]$.

\section{Effect of a decrease in brain blood volume on} cerebrovascular disease during and after hemodialysis Cerebral infarction often occurs within $6 \mathrm{~h}$ after the end of hemodialysis [7]. A decrease in blood pressure has been reported to be more pronounced in patients who developed infarction soon after the end of dialysis than those who developed it $6 \mathrm{~h}$ or longer after the end of dialysis [1]. The mechanisms of hemodialysis-induced cerebral infarction include a reduction in cerebral blood flow due to increased blood viscosity and a fall in blood pressure associated with water removal or orthopedic hypotension following sitting up or standing up after dialysis.

Elderly patients and those with diabetes mellitus (DM) have severe systemic atherosclerosis and are prone to develop dialysis-related hypotension and orthostatic hypotension. Hemodynamic brain infarction might be induced in these patients because of a damaged brain autoregulation system [8]. To evaluate cerebral circulation during orthostasis in patients with DM, we examined changes in mean blood flow velocity in the middle cerebral artery during $60^{\circ}$ of head-up tilt for $5 \mathrm{~min}$ in patients with DM by using transcranial Doppler sonography. We compared our findings with those in hemodialysis patients without DM in the supine position
[9]. We found a significant decrease in cerebral blood flow velocity during tilt of equal magnitude in both groups before hemodialysis, despite differences in the level of hypotension, whereas reduction in cerebral blood flow velocity and a decrease in mean blood pressure were more marked in DM after hemodialysis (Fig. 1). Therefore, orthostasis can cause hemodynamically mediated brain damage after hemodialysis, especially in patients with DM.

\section{Prevention of cerebrovascular disease Anticoagulant therapy for hemodialysis patients with atrial fibrillation}

\section{Effect of atrial fibrillation on thromboembolic} complications Whether atrial fibrillation increases thromboembolic complications in hemodialysis patients is controversial. Vázquez et al. [10, 11] reported that atrial fibrillation is relatively prevalent and its presence increases mortality and the risk of ischemic stroke. However, Wiesholzer et al. [12] reported that atrial fibrillation itself is not associated with an increased risk of stroke in patients on maintenance hemodialysis. Furthermore, Genovesi et al. [13] demonstrated that rates of stroke did not significantly differ by atrial fibrillation status, although patients with atrial fibrillation were

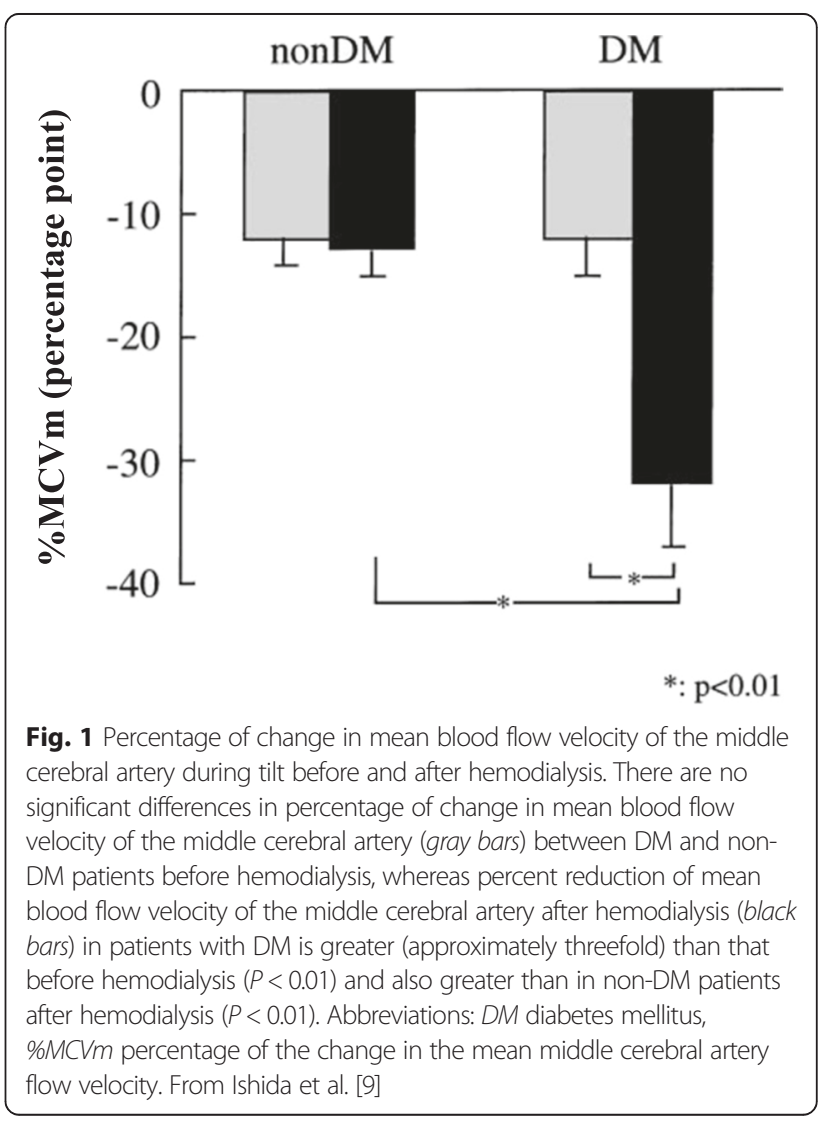


hospitalized more frequently than those without atrial fibrillation.

\begin{abstract}
Advantages and disadvantages of administration of warfarin Whether warfarin should be administered to chronic hemodialysis patients with atrial fibrillation is also controversial. Chan et al. [14] investigated the association between this medication and new stroke, mortality, and hospitalization in a retrospective cohort analysis of 1671 incident hemodialysis patients with preexisting atrial fibrillation. They showed that warfarin use was associated with a significantly increased risk for new stroke. They also demonstrated that warfarin users who received no international normalized ratio monitoring had the highest risk for stroke compared with nonusers. Thereafter, similar, large-scale, observational studies were conducted, and they concluded that warfarin use is not beneficial in reducing the risk of stroke, but it is associated with a higher bleeding risk in patients with atrial fibrillation undergoing dialysis [15-17].
\end{abstract}

In contrast, only one large-scale study has recently shown usefulness of warfarin in hemodialysis patients with atrial fibrillation. Olesen et al. [18] conducted a study using Danish national registries in which all 132,372 patients, including 3587 with non-dialysis-dependent CKD and 901 with ESKD, were identified to be discharged from the hospital with a diagnosis of non-valvular atrial fibrillation between 1997 and 2008. They estimated the risk of stroke or systemic thromboembolism and bleeding with the use of time-dependent Cox regression analyses and compared the effects of treatment with warfarin, aspirin, or both in patients with or without CKD. They showed that the risk of stroke or systemic thromboembolism was increased in patients with CKD and ESKD compared with those without CKD, and such risk was decreased by treatment with warfarin in both groups of patients with CKD and ESKD.

However, there were several limitations to this study. A larger proportion of dialysis patients had unusually low HAS-BLED scores (HAS-BLED score 2-35 \% (312/ 901); 0 or $1-43 \%$ (390/901)). Contrary to Shah's study and DOPPS, dialysis patients had a low prevalence of diabetes mellitus (14 \% (129/901)) and hypertension $(54 \%(486 / 901))$. It is possible that a selection bias of healthier patients undergoing dialysis could explain the reason for the decreased risk of stroke with warfarin use in the study by Olesen et al.

As described above, the usefulness of warfarin has not been established in hemodialysis patients with atrial fibrillation in most recently reported large-scale, observational studies (Fig. 2) [17]. In Japan, guidelines for management of cardiovascular disease in patients on chronic hemodialysis published by the Japanese Society for Dialysis Therapy [1] suggest that warfarin therapy should not be routinely performed for atrial fibrillation. However, if considered beneficial, such therapy is desirable to use by maintaining the prothrombin time-international normalized ratio at $<2.0$. The Canadian Cardiovascular Society Atrial Fibrillation Guidelines [19] also suggest that patients with an estimated glomerular filtration rate $<15 \mathrm{~mL} /$ $\min / 1.73 \mathrm{~m}^{2}$ (on dialysis) should not routinely receive either oral anticoagulants or aspirin for prevention of stroke in atrial fibrillation.

Novel oral anticoagulants for patients with CKD Recently, novel oral anticoagulants (NOACs), such as dabigatran, rivaroxaban, apixaban, and edoxaban, were developed and clinically approved. These drugs are superior to warfarin for prevention of ischemic stroke, systemic embolic events, intracranial hemorrhage, and all-cause mortality [20].

Because these drugs are excreted from the body via the kidney, using these drugs in patients with severe CKD is considered difficult. A systematic review of randomized, controlled trials was conducted in patients with CKD and defined creatinine clearance (Ccr) as 30$50 \mathrm{~mL} / \mathrm{min}$. This review demonstrated that the use of NOACs in select patients with CKD is effective and safe, similar to warfarin [21].

Recently, the relationship between NOACs and activated partial thromboplastin time (aPTT) has been focused in the careful monitoring. Shimomura et al. [22] analyzed plasma dabigatran concentration and aPTT at various time points following administration of oral dabigatran in 149 patients with non-valvular atrial fibrillation. They demonstrated that there was a significant correlation between plasma dabigatran concentrations and aPTT and concluded that considering the pharmacokinetics of dabigatran, aPTT can be used as an index for risk screening for excess dabigatran concentrations in Japanese patients. However, they also showed that significantly higher dabigatran concentrations were observed in samples from patients with reduced renal function (Ccr $<50 \mathrm{~mL} / \mathrm{min}$ ) compared with those with normal renal function (Ccr $\geq 50 \mathrm{~mL} / \mathrm{min}$ ), and the correlation was lower when plasma dabigatran concentrations were higher, suggesting the difficulties for monitoring of dabigatran concentrations using aPTT in CKD patients.

The use of NOACs in dialysis patients is discouraged because these drugs can bioaccumulate to precipitate inadvertent bleeding. However, in the USA, dabigatran and rivaroxaban use in dialysis patients with atrial fibrillation has steadily risen to where $5.9 \%$ of anticoagulated dialysis patients are started on dabigatran or rivaroxaban. Chan et al. [23] reported that in covariate-adjusted Poisson regression, dabigatran and rivaroxaban were associated with a higher risk of hospitalization or death from bleeding compared with warfarin. Additionally, the 


\begin{tabular}{|c|c|c|c|c|c|}
\hline \multirow{2}{*}{$\begin{array}{l}\text { Author } \\
\text { (publication year) } \\
\text { Chan (2009) }\end{array}$} & \multicolumn{2}{|l|}{ Outcome (Age) } & \multicolumn{2}{|c|}{ Hazard ratio } & $95 \% \mathrm{CI}$ \\
\hline & Stroke/Death & & $\#$ & 1.93 & $1.29-2.90$ \\
\hline Wizemann (2010) & Stroke/Death ( $\leq 65$ years) & $\mapsto$ & 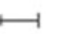 & 1.29 & $0.45-3.68$ \\
\hline Wizemann (2010) & Stroke/Death (66-75 years) & & -1 & 1.35 & $0.69-2.63$ \\
\hline Wizemann (2010) & Stroke/Death ( $>75$ years) & & 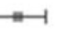 & 2.17 & $1.04-4.53$ \\
\hline Winkelmayer (2011) & Ischemic stroke & $\mapsto$ & & 0.92 & $0.61-1.37$ \\
\hline Winkelmayer (2011) & Hemorrhagic stroke & & $\because 1$ & 2.38 & $1.15-4.96$ \\
\hline Olesen (2012) & Stroke/Death & $\mapsto-1$ & & 0.44 & $0.26-0.74$ \\
\hline \multirow[t]{3}{*}{ Shah (2014) } & Ischemic stroke & & & 1.14 & $0.78-1.67$ \\
\hline & & Favors warfarin & \multicolumn{2}{|c|}{ Does not favor } & \\
\hline & & 0.1 & & 100 & \\
\hline
\end{tabular}

Fig. 2 Warfarin use and the risk for stroke in patients with atrial fibrillation undergoing dialysis. Results of evidence from previous published studies of warfarin use and the risk for stroke in patients with atrial fibrillation undergoing dialysis are shown. Abbreviation: $\mathrm{Cl}$ confidence interval. From Shah et al. [17]

risk of hemorrhagic death was even larger with dabigatran and rivaroxaban relative to warfarin, although there were too few events in the study to detect meaningful differences in stroke and arterial embolism between the drug groups [23].

\section{Prevalence of cerebral microbleeds and risk of brain hemorrhage}

Cerebral microbleeds appearing as low-signal-intensity areas by $\mathrm{T} 2 \%$-weighted magnetic resonance imaging (MRI) are frequently detected in patients with hypertension and those with a history of cerebrovascular disorders. Cerebral microbleeds are also frequently observed in CKD patients, especially in ESKD patients [24, 25].

Cerebral microbleeds have been reported to affect the occurrence of cerebral hemorrhage [26-29]. Naganuma et al. [29] performed cranial MRI, including T2\%-weighted MRI, on 179 hemodialysis patients with no past history of cerebrovascular events and followed them prospectively until death or renal transplantation. They showed that intracerebral hemorrhage occurred in only one of 134 $(0.7 \%)$ patients without cerebral microbleeds, whereas it occurred in 11 of 45 (24.4\%) patients with cerebral microbleeds during a median follow-up period of 5.0 years. This finding suggests that hemodialysis patients with cerebral microbleeds should be carefully monitored for future onset of intracerebral hemorrhage. However, whether the risk of cerebral hemorrhage is increased by antithrombotic therapy is unclear.

\section{Hypotension during hemodialysis sessions}

Hypotension during hemodialysis sessions might decrease brain blood flow and induce brain infarction. In our previous study using MRI, we found a positive association between the numbers of dialysis-related hypotension episodes, i.e., a sudden drop in blood pressure during
HD, was arbitrarily defined as a fall in systolic blood pressure $>50 \mathrm{mmHg}$ within $30 \mathrm{~min}$ of $\mathrm{HD}$, associated with clinical symptoms such as fatigue, clouding of consciousness, muscle cramps, or other symptoms associated with hypoperfusion of the peripheral or central nervous system, identified from the medical records during 3 years with progression of frontal brain atrophy (Fig. 3) [30].

Therefore, reducing the ultrafiltration rate per hour during hemodialysis is important. Consequently, education of patients on salt restriction is important to reduce intradialytic weight gain. Administration of vasopressor drugs is available and effective to prevent hypotension during and after hemodialysis sessions. We previously reported the effect of vasopressor drugs, such as midodrine hydrochloride and droxidopa, against a decrease in brain blood flow due to orthostatic hypotension after a hemodialysis session (Fig. 4) [31].

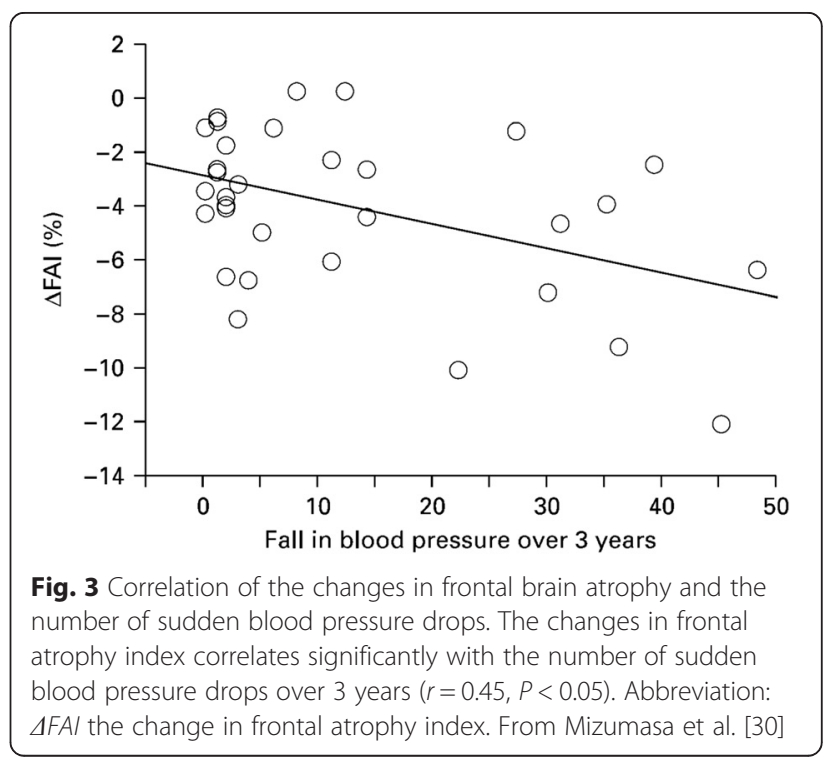




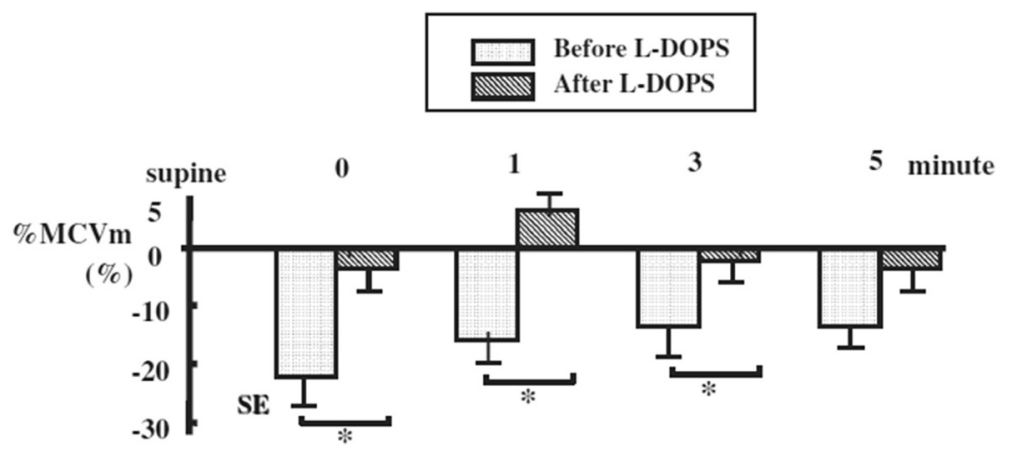

Fig. 4 Serial changes in \%MCVm after head-up tilt test in patients treated with L-DOPS. The serial changes in \%MCVm during the 5-min head-up tilt test, before and after 4-week L-DOPS treatment at each period are shown. L-DOPS improves \%MCVm decrement throughout the 5-min head-up tilt test. Data are mean \pm SEM. ${ }^{*} P<0.05$ vs. before L-DOPS. Abbreviations: \%MCVm percentage of the change in the mean middle cerebral artery flow velocity, L-DOPS L-threo-3,4-dihydroxyphenylserine. From Fujisaki et al. [31]

\section{Carotid endarterectomy and carotid artery stenting for carotid artery stenosis}

The prognosis after carotid endarterectomy (CEA) for severe carotid artery stenosis in patients with CKD has been shown to be poor [32], while better effectiveness of CEA was reported in those patients compared with nonCKD patients [33]. With regard to carotid artery stenting (CAS), poorer prognosis was also reported in CKD patients compared with non-CKD patients [34].

Using the United States Renal Data System (USRDS) databases, Yuo et al. [35] examined the prognosis in 2131 dialysis patients (1805 CEA, 326 CAS) who underwent CEA or CAS for asymptomatic disease from 2005 to 2008. They showed that the combined stroke or death rate was $10.2 \%$ at 30 days and $33.5 \%$ at 1 year and concluded that patients on dialysis have high perioperative and long-term stroke or death rates after CEA or CAS for asymptomatic stenosis, with a median survival of 2.5 years, which is less than that recommended by current guidelines [36]. This finding emphasizes the importance of a minimum life expectancy of at least 3 years for there to be a benefit in asymptomatic patients undergoing CEA. According to these findings, the indications for these procedures must be carefully evaluated.

In contrast, Okawa et al. [37] demonstrated that of 12 hemodialysis patients with carotid artery stenosis undergoing 15 CEAs, none of them showed periprocedural complications, including stroke and myocardial infarction. They concluded that CEA may be effective for prevention of stroke in hemodialysis patients.

\section{Treatment and management of cerebrovascular disease Management of renal failure during the acute phase of cerebrovascular disease}

Intracranial pressure autoregulation collapses immediately after the onset of brain infarction [38], and the risk of expansion of hematoma is high within $24 \mathrm{~h}$ after the onset of cerebral hemorrhage [39]. Therefore, avoiding dialysis on the day of onset is desirable. Consequently, the need for dialysis should be carefully evaluated. If dialysis is performed, procedures such as peritoneal dialysis, continuous hemodiafiltration, and hemodialysis with restricted blood flow, which are less likely to increase intracranial pressure compared with usual intermittent hemodialysis, are recommended as the dialysis techniques to be used during the acute period. Rapid and massive removal of water should be avoided because it exacerbates brain ischemia. Nafamostat mesilate is recommended to use as an anticoagulant during hemodialysis if hemorrhagic stroke and hemorrhagic brain infarction are concerned [1].

\section{Thrombolytic therapy}

In the last decade, thrombolytic therapy using recombinant tissue plasminogen activator (rt-PA) has been applied in the clinical setting for patients with hyperacute phase brain infarction. However, a worse prognosis with a higher mortality and incidence of brain hemorrhage has been reported in patients with CKD compared with those without CKD [40, 41].

Because thrombolytic therapy has not been contraindicated for hemodialysis patients, it has been applied to hemodialysis patients in a few cases. Naganuma et al. [42] reported the effectiveness of rt-PA therapy in four stroke patients receiving maintenance hemodialysis with a unique complication of ectopic cortical hematoma.

Tariq et al. [43] analyzed the data of 82,142 patients from the Nationwide Inpatient Sample for all thrombolytictreated patients presenting with acute ischemic stroke in the USA between 2002 and 2009. They showed a twofold higher likelihood of in-hospital mortality associated with administration of intravenous thrombolytic therapy in 1072 dialysis patients, requiring careful assessment of the risk-benefit ratio in this population. A systematic review recently reported by Jung et al. [44] demonstrated that patients with CKD had a higher risk of symptomatic intracerebral hemorrhage and mortality, 
and were likely to have an increased risk of poor functional status.

In spite of high risk of thrombolytic therapy for ESKD patients on hemodialysis as described above, this therapy is one of the important modality of treatment for patients with hyperacute phase brain infarction. Thus, if a hemodialysis patient develops cerebrovascular disease during or shortly after hemodialysis, the patient should be transported to expert facilities early after the onset [1]. Accordingly, creating a system and preparing to be able to transport these patients as soon as possible after the onset of are considered to be important in the hemodialysis facilities.

\section{Endovascular mechanical thrombectomy}

Recently, mechanical thrombectomy has been applied for patients with ischemic stroke who are invalid or contraindicated for thrombolytic therapy. More recently, randomized, controlled trials showing the usefulness of mechanical thrombectomy for patients with acute brain infarction due to intracranial major artery stenosis have been published [45-49]. However, the effectiveness of mechanical thrombectomy in CKD patients is unknown because all of these trials provided no or little information on renal function and proteinuria in the participants.

Saeed et al. [50] analyzed 2313 dialysis patients with ischemic stroke using data from the Nationwide Inpatient Sample including dialysis patients presenting with acute ischemic stroke in the USA between 2005 and 2010. Among these, 1398 (60\%) received intravenous thrombolytic therapy and 915 (40\%) were treated with endovascular mechanical thrombectomy. They showed that endovascular mechanical thrombectomy was associated with lower inhospital mortality and moderate-to-severe disability, even after adjusting for age, sex, and potential confounders. According to these findings, the preferential use of endovascular mechanical thrombectomy might be warranted in this patient population.

\section{Conclusions}

Because of the specific pathophysiology in patients with CKD, especially those with ESKD, prevention and management of cerebrovascular disease are different from those without CKD. However, to date, there is inadequate evidence on how to prevent and manage cerebrovascular disease in this patient population. Further accumulation of evidence is needed to establish prevention and management of cerebrovascular disease in CKD patients.

\section{Competing interests}

The authors declare that they have no competing interests.

\section{Authors' contributions}

$\mathrm{KT}$ and KF have been involved in drafting, revising, and editing the manuscript. $K T$ takes responsibility that this study has been reported honestly, accurately, and transparently. Both authors read and approved the final manuscript.

\section{Acknowledgements}

We thank Edanz Editing (http://www.edanzediting.co.jp/) for the careful reading and editing of our manuscript.

Received: 18 November 2015 Accepted: 26 April 2016

Published online: 13 July 2016

\section{References}

1. Hirakata H, Nitta K, Inaba M, Shoji T, Fujii H, Kobayashi S, et al. Japanese Society for Dialysis Therapy. Japanese Society for Dialysis Therapy guidelines for management of cardiovascular diseases in patients on chronic hemodialysis. Ther Apher Dial. 2012;16:387-435.

2. Tsuruya K, Hirakata H. Japanese Society for Dialysis Therapy guidelines for management of cardiovascular diseases in patients on chronic hemodialysis. Ther Apher Dial. 2012;16:384-6.

3. Lee M, Saver JL, Chang KH, Liao HW, Chang SC, Ovbiagele B. Low glomerular filtration rate and risk of stroke: meta-analysis. BMJ. 2010;341:C4249.

4. Kumai Y, Kamouchi M, Hata J, Ago T, Kitayama J, Nakane H, et al. Proteinuria and clinical outcomes after ischemic stroke. Neurology. 2012;78:1909-15.

5. Kuwashiro T, Sugimori H, Ago T, Kamouchi M, Kitazono T, FSR Investigators. Risk factors predisposing to stroke recurrence within one year of noncardioembolic stroke onset: the Fukuoka Stroke Registry. Cerebrovasc Dis. 2012;33:141-9.

6. Kawamura M, Fijimoto S, Hisanaga S, Yamamoto Y, Eto T. Incidence, outcome, and risk factors of cerebrovascular events in patients undergoing maintenance hemodialysis. Am J Kidney Dis. 1998;31:991-6.

7. Onoyama K, Kumagai H, Miishima T, Tsuruda H, Tomooka S, Motomura K, et al. Incidence of strokes and its prognosis in patients on maintenance hemodialysis. Jpn Heart J. 1986;27:685-91.

8. Kim YS, Davis SC, Truijen J, Stok WJ, Secher NH, van Lieshout JJ. Intensive blood pressure control affects cerebral blood flow in type 2 diabetes mellitus patients. Hypertension. 2011;57:738-45.

9. Ishida I, Hirakata H, Sugimori H, Omae T, Hirakata E, Ibayashi S, et al. Hemodialysis causes severe orthostatic reduction in cerebral blood flow velocity in diabetic patients. Am J Kidney Dis. 1999;34:1096-104.

10. Vázquez E, Sánchez-Perales C, Borrego F, Garcia-Cortés MJ, Lozano C, Guzmán M, et al. Influence of atrial fibrillation on the morbido-mortality of patients on hemodialysis. Am Heart J. 2000;140:886-90.

11. Vazquez E, Sanchez-Perales C, Garcia-Garcia F, Castellano P, Garcia-Cortes MJ, Liebana A, et al. Atrial fibrillation in incident dialysis patients. Kidney Int. 2009;76:324-30

12. Wiesholzer M, Harm F, Tomasec G, Barbieri G, Putz D, Balcke P. Incidence of stroke among chronic hemodialysis patients with nonrheumatic atrial fibrillation. Am J Nephrol. 2001;21:35-9.

13. Genovesi S, Vincenti A, Rossi E, Pogliani D, Acquistapace I, Stella A, et al. Atrial fibrillation and morbidity and mortality in a cohort of long-term hemodialysis patients. Am J Kidney Dis. 2008:51:255-62.

14. Chan KE, Lazarus JM, Thadhani R, Hakim RM. Warfarin use associates with increased risk for stroke in hemodialysis patients with atrial fibrillation. J Am Soc Nephrol. 2009;20:2223-33.

15. Wizemann V, Tong L, Satayathum S, Disney A, Akiba T, Fissell RB, et al. Atrial fibrillation in hemodialysis patients: clinical features and associations with anticoagulant therapy. Kidney Int. 2010;77:1098-106.

16. Winkelmayer WC, Liu J, Setoguchi S, Choudhry NK. Effectiveness and safety of warfarin initiation in older hemodialysis patients with incident atrial fibrillation. Clin J Am Soc Nephrol. 2011;6:2662-8.

17. Shah M, Avgil Tsadok M, Jackevicius CA, Essebag V, Eisenberg MJ, Rahme E, et al. Warfarin use and the risk for stroke and bleeding in patients with atrial fibrillation undergoing dialysis. Circulation. 2014;129:1196-203.

18. Olesen JB, Lip GY, Kamper AL, Hommel K, Køber L, Lane DA, et al. Stroke and bleeding in atrial fibrillation with chronic kidney disease. N Engl I Med. 2012;367:625-35.

19. Skanes AC, Healey JS, Cairns JA, Dorian P, Gillis AM, McMurtry MS, et al. Focused 2012 update of the Canadian Cardiovascular Society atrial fibrillation guidelines: recommendations for stroke prevention and rate/ rhythm control. Can J Cardiol. 2012;28:125-36. 
20. Ruff CT, Giugliano RP, Braunwald E, Hoffman EB, Deenadayalu N, Ezekowitz MD, et al. Comparison of the efficacy and safety of new oral anticoagulants with warfarin in patients with atrial fibrillation: a meta-analysis of randomised trials. Lancet. 2014;383:955-62.

21. Harel Z, Sholzberg M, Shah PS, Pavenski K, Harel S, Wald R, et al. Comparisons between novel oral anticoagulants and vitamin $\mathrm{K}$ antagonists in patients with CKD. J Am Soc Nephrol. 2014;25:431-42.

22. Shimomura D, Nakagawa $Y$, Kondo H, Tamura T, Amano M, Hayama Y, et al. Relationship between plasma dabigatran concentration and activated partial thromboplastin time in Japanese patients with non-valvular atrial fibrillation. J Arrhythm. 2015;31:183-8.

23. Chan KE, Edelman ER, Wenger JB, Thadhani RI, Maddux FW. Dabigatran and rivaroxaban use in atrial fibrillation patients on hemodialysis. Circulation. 2015;131:972-9.

24. Watanabe A. Cerebral microbleeds and intracerebral hemorrhages in patients on maintenance hemodialysis. J Stroke Cerebrovasc Dis. 2007;16:30-3.

25. Shima H, Ishimura E, Naganuma T, Yamazaki T, Kobayashi I, Shidara K, et al. Cerebral microbleeds in predialysis patients with chronic kidney disease. Nephrol Dial Transplant. 2010;25:1554-9.

26. Nighoghossian N, Hermier M, Adeleine P, Blanc-Lasserre K, Derex L, Honnorat J, et al. Old microbleeds are a potential risk factor for cerebral bleeding after ischemic stroke: a gradient-echo $\mathrm{T}^{*}$-weighted brain MRI study. Stroke. 2002;33:735-42.

27. Imaizumi T, Horita $Y$, Hashimoto $Y$, Niwa J. Dotlike hemosiderin spots on $T 2^{*}$-weighted magnetic resonance imaging as a predictor of stroke recurrence: a prospective study. J Neurosurg. 2004;101:915-20.

28. Naka H, Nomura E, Takahashi T, Wakabayashi S, Mimori Y, Kajikawa H, et al. Combinations of the presence or absence of cerebral microbleeds and advanced white matter hyperintensity as predictors of subsequent stroke types. AJNR Am J Neuroradiol. 2006;27:830-5.

29. Naganuma T, Takemoto $Y$, Shoji T, Ishimura E, Okamura M, Nakatani T. Cerebral microbleeds predict intracerebral hemorrhage in hemodialysis patients. Stroke. 2015;46:2107-12.

30. Mizumasa T, Hirakata H, Yoshimitsu T, Hirakata E, Kubo M, Kashiwagi M, et al. Dialysis-related hypotension as a cause of progressive frontal lobe atrophy in chronic hemodialysis patients: a 3-year prospective study. Nephron Clin Pract. 2004;97:c23-30.

31. Fujisaki $K$, Kanai $H$, Hirakata $H$, Nakamura S, Koga $Y$, Hattori F, et al. Midodrine hydrochloride and L-threo-3,4-dihydroxy-phenylserine preserve cerebral blood flow in hemodialysis patients with orthostatic hypotension. Ther Apher Dial. 2007;1:49-55.

32. Mathew A, Devereaux PJ, O'Hare A, Tonelli M, Thiessen-Philbrook H, et al. Chronic kidney disease and postoperative mortality: a systematic review and meta-analysis. Kidney Int. 2008;73:1069-81.

33. Mathew A, Eliasziw M, Devereaux PJ, Merino JG, Barnett HJ, Garg AX, et al. Carotid endarterectomy benefits patients with CKD and symptomatic highgrade stenosis. J Am Soc Nephrol. 2010;21:145-52.

34. AbuRahma AF, Alhalbouni S, Abu-Halimah S, Dean LS, Stone PA. Impact of chronic renal insufficiency on the early and late clinical outcomes of carotid artery stenting using serum creatinine vs glomerular filtration rate. J Am Coll Surg. 2014;218:797-805.

35. Yuo TH, Sidaoui J, Marone LK, Makaroun MS, Chaer RA. Revascularization of asymptomatic carotid stenosis is not appropriate in patients on dialysis. J Vasc Surg. 2015;61:670-4

36. Ricotta JJ, Aburahma A, Ascher E, Eskandari M, Faries P, Lal BK, et al. Updated Society for Vascular Surgery guidelines for management of extracranial carotid disease. J Vasc Surg. 2011;54:832-6.

37. Okawa M, Ueba T, Ogata T, Abe H, Higashi T, Inoue T. Long-term morbidity and mortality of carotid endarterectomy in patients with end-stage renal disease receiving hemodialysis. J Stroke Cerebrovasc Dis. 2014;23:545-9.

38. Kazui S, Naritomi H, Yamamoto H, Sawada T, Yamaguchi T. Enlargement of spontaneous intracerebral hemorrhage. Incidence and time course. Stroke. 1996;27:1783-7.

39. Rose JC, Mayer SA. Optimizing blood pressure in neurological emergencies. Neurocrit Care. 2004;1:287-99.

40. Hirano T. Thrombolysis and hyperacute reperfusion therapy for stroke in renal patients. Contrib Nephrol. 2013;179:110-8.

41. Toyoda K, Ninomiya T. Stroke and cerebrovascular diseases in patients with chronic kidney disease. Lancet Neurol. 2014;13:823-33.

42. Naganuma M, Mori M, Nezu T, Makihara N, Koga M, Okada Y, et al. Intravenous recombinant tissue plasminogen activator therapy for stroke patients receiving maintenance hemodialysis: the Stroke Acute Management with Urgent Risk-Factor Assessment and Improvement (SAMURAI) rt-PA registry. Eur Neurol. 2011;66:37-41.

43. Tariq N, Adil MM, Saeed F, Chaudhry SA, Qureshi Al. Outcomes of thrombolytic treatment for acute ischemic stroke in dialysis-dependent patients in the United States. J Stroke Cerebrovasc Dis. 2013;22:e354-9.

44. Jung JM, Kim HJ, Ahn H, Ahn IM, Do Y, Choi JY, et al. Chronic kidney disease and intravenous thrombolysis in acute stroke: a systematic review and meta-analysis. J Neurol Sci. 2015;358:345-50.

45. Berkhemer OA, Fransen PS, Beumer D, van den Berg LA, Lingsma HF, Yoo $\mathrm{AJ}$, et al. A randomized trial of intraarterial treatment for acute ischemic stroke. N Engl J Med. 2015;372:11-20.

46. Campbell BC, Mitchell PJ, Kleinig TJ, Dewey HM, Churilov L, Yassi N, et al. Endovascular therapy for ischemic stroke with perfusion-imaging selection. N Engl J Med. 2015:372:1009-18.

47. Goyal M, Demchuk AM, Menon BK, Eesa M, Rempel JL, Thornton J, et al. Randomized assessment of rapid endovascular treatment of ischemic stroke. N Engl J Med. 2015;372:1019-30.

48. Saver JL, Goyal M, Bonafe A, Diener HC, Levy El, Pereira VM, et al. Stentretriever thrombectomy after intravenous t-PA vs. t-PA alone in stroke. $\mathrm{N}$ Engl J Med. 2015;372:2285-95.

49. Jovin TG, Chamorro A, Cobo E, de Miquel MA, Molina CA, Rovira A, et al Thrombectomy within 8 hours after symptom onset in ischemic stroke. N Engl J Med. 2015;372:2296-306.

50. Saeed F, Adil MM, Piracha BH, Qureshi Al. Outcomes of endovascular versus intravenous thrombolytic treatment for acute ischemic stroke in dialysis patients. Int J Artif Organs. 2014;37:727-33.

\section{Submit your next manuscript to BioMed Central and we will help you at every step:}

- We accept pre-submission inquiries

- Our selector tool helps you to find the most relevant journal

- We provide round the clock customer support

- Convenient online submission

- Thorough peer review

- Inclusion in PubMed and all major indexing services

- Maximum visibility for your research

Submit your manuscript at www.biomedcentral.com/submit
) Biomed Central 